\title{
Effects of temperature and concentration of La in the form of A1 transverse optical phonon in the $\mathrm{PbTiO}_{3}$ system
}

\section{(Efeitos da temperatura e concentração de La na forma de fótons ópticos transversais A1 no sistema $\mathrm{PbTiO}_{3}$ )}

\author{
M. R. Joya ${ }^{1^{*}}$, J. J. Barba-O', P. S. Pizani ${ }^{2}$ \\ ${ }^{1}$ Departamento de Física, Universidad Nacional de Colombia,Carrera 45 N. 26-85 - Bogotá D. C., Colombia \\ ${ }^{2}$ Departamento de Física, Universidade Federal de S. Carlos, Rod. Washington Luiz, km 235, \\ C.P. 676, S. Carlos, SP 13565-905
}

\begin{abstract}
The structural phase transition from ferroelectric to paraelectric was studied by Raman scattering in the ceramic lead titanate $\left(\mathrm{PbTiO}_{3}\right)$ doped with lanthanum $(\mathrm{La})$. Al vibrational mode contains some sub-peaks that have been associated in literature with $\mathrm{PbTiO}_{3}$ concentration $(\mathrm{Ca}, \mathrm{Ba})$, and effects of high temperatures as it approaches the Curie temperature (Tc). Raman new study shows that the anomalous behavior of the A1 mode is not only caused by the effects of concentration or temperature near Tc, but by anharmonicity and defects in the network in the $\mathrm{PbTiO}_{3}$ thermodynamically are inevitable. This effect was studied by a wide temperature range from $10 \mathrm{~K}$ to Tc in each sample $(\mathrm{La}=0,5,10,15,20 \%)$, showing that the effect depends not only on the high temperatures in the pure PT.
\end{abstract}

Keywords: $\mathrm{PbTiO}_{3}$, ferroelectric, paraelectric, anharmonicity.

\section{Resumo}

A transição de fase estrutural de ferroelétrico para paraelétrico foi estudada por espalhamento Raman em cerâmicas de titanato de chumbo ( $\left.\mathrm{PbTiO}_{3}\right)$ dopadas com lantânio ( $\mathrm{La}$ ). O modo vibracional Al contém alguns picos que tem sido associados na literatura com a concentração de $\mathrm{PbTiO}_{3}(\mathrm{Ca}, \mathrm{Ba})$, e os efeitos das altas temperaturas ao se aproximar da temperatura de Curie (Tc). Um novo estudo Raman mostra que o comportamento anômalo do modo Al não é apenas causado pelos efeitos da concentração ou da temperatura próxima de Tc, mas por anarmonicidade e defeitos na rede do $\mathrm{PbTiO}_{3}$ são termodinamicamente inevitáveis. Este efeito foi estudado em uma ampla faixa de temperatura de $10 \mathrm{~K}$ a Tc em cada amostra ( $L a=0,5,10,15,20 \%)$, mostrando que o efeito depende não somente das altas temperaturas no PT puro.

Palavras-chave: $\mathrm{PbTiO}_{3}$, ferroelétrico, paraelétrico, anarmonicidade.

\section{INTRODUCTION}

The $\mathrm{PbTiO}_{3}(\mathrm{PT})$ is one of most studied ferroelectric materials in basic research and industrial applications [3-11]. In the literature there are many arguments about the nature of the phase transition of $\mathrm{PbTiO}_{3}$ such as a displacement or order disorder transition. Raman Spectroscopy studies have shown that this system undergoes a typical displacement ferroelectric phase transition observed by the soft sub damping of the low frequency fanon $[1,5,13]$. In a study by Burns et al [6] and others $[1,2,9,12]$, show that the optical transverse mode E1 of lower frequency can observe the transition of ferroelectric-paraelectric phase in the PLT. On the other hand, the optical cross A1 as first studied by Foster et al [12] and found in $\pm 148 \mathrm{~cm}^{1}$ show that it is also indicative of the structural phase transition; however, the author discusses the anomalous behavior of A1 but gives no definitive explanation of the vibrational mode shape. An explanation of A1 mode given by Foster [12], says that the A1 has a nature so inharmonious in the interatomic effective potential. He also says that the A1 and E1 mode must be crossed at high temperatures, however the study was limited in $225 \mathrm{~K}-400 \mathrm{~K}$ and therefore the behavior for high temperatures could not observed.

Other authors [1] make a systematic study of the abnormal form of A1 mode to temperatures in $300 \mathrm{~K} \leq 700$ $\mathrm{K}$, and returns to the anharmonicity model and compares the vibrational mode of PT doped with Bario (Ba). This study concludes that the A1 mode of pure PT is not related to the anharmonicity but thermodynamic defect in the network to high temperatures leading the multiphonons process to high temperatures. Some theoretical studies have emerged about the subject without the final conclusion about the failure mode in the form A1 $[12,13]$. It is true that there are some 
studies for the abnormally A1 but all the explanations for high temperatures, and only exists in the literature study for the PT- doped with Ba to high temperatures, attributing the effect to defects on the network by vacancies [1].

In this study, we have investigated the anomalous of the A1 phonon in the PT-doped with La. We note that the phenomenon occurs to low temperatures and not only to high temperatures for the pure PT. Therefore, we conclude that it requires a more systematic theoretical further study to clarify the origin of the anomalous behavior of A1 mode in the whole range of temperatures and for different doping in PT, since it is considered one of the main modes in the transition from tetragonal to cubic system. Studies of behavior of this peak were not found in the literature for low temperatures and different doping. This is the reason that leads us to show that the effect is also observed to low temperatures and for different La concentrations.

\section{EXPERIMENTAL}

The radiation source for the study was a laser Raman Innova $70 \mathrm{C}$ with the line of $\lambda=514.5 \mathrm{~nm}$ and as a dispersive system was used spectrometer Jobin-Yvon T64000 and as detection system a CCD camera. The system was operated in the micro-Raman mode. For low temperatures we used a special cryostat for micro-Raman can be operated between 8 to $320 \mathrm{~K}$. High temperatures a micro-furnace with a quartz window that allows the micro-Raman measurements up to $1500{ }^{\circ} \mathrm{C}$.

\section{RESULTS AND DISCUSSION}

Fig. 1 shows the behavior of the peak A1 in the pure $\mathrm{PT}$, from low to high temperatures or near of the $\mathrm{Tc}$ temperature. As shown, the A1 and E1 mode are going to lower frequencies with increasing temperatures. This behavior allows to observe the structural phase transition from tetragonal to cubic in the PL.

Fig. 2 shows the enlargement for the A1 mode in the simple of $5 \%$ of $\mathrm{La}$, at a temperature of $10 \mathrm{~K}$. As shown, this mode has a complex way consisting of several sub-peaks. It is says that this mode is related to a double potential well in the PT ferroelectric system. Thus, the anharmonic double potential well is the source of the sub-peaks at high temperatures. According to the anharmonic model the subpeaks correspond to vibrational transitional from a quantum state. This being true to high temperatures, indicating that it is also occurs at low temperatures, as shown in the Fig. 2 in which there is a clear anomaly in the shape of the A1 peak. The way is diverting some Lorenziana function which should match a single peak at low temperatures.

Fig. 3 shows the mode behavior at a temperature of $100 \mathrm{~K}$, in the left figure the general mode behavior with the concentration of lanthanum $\left(\mathrm{Pb}_{1-\mathrm{x}} \mathrm{La}_{\mathrm{x}} \mathrm{TiO}_{3}\right)$. In the right figure we observe the A1 mode for the $5 \%$ of La. As the concentration of La increases is difficult to separate the peaks due to these lengthen. However, we observe that there

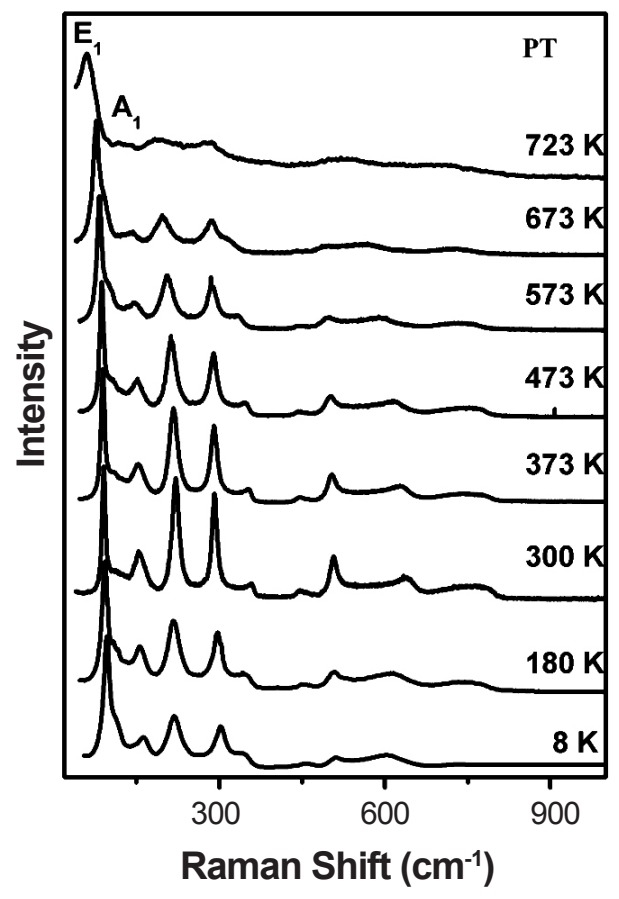

Figure 1: A1 vibrational mode behavior at different temperatures for pure PT.

[Figura 1: Comportamento do modo vibracional Al em diferentes temperaturas para o PT puro.]

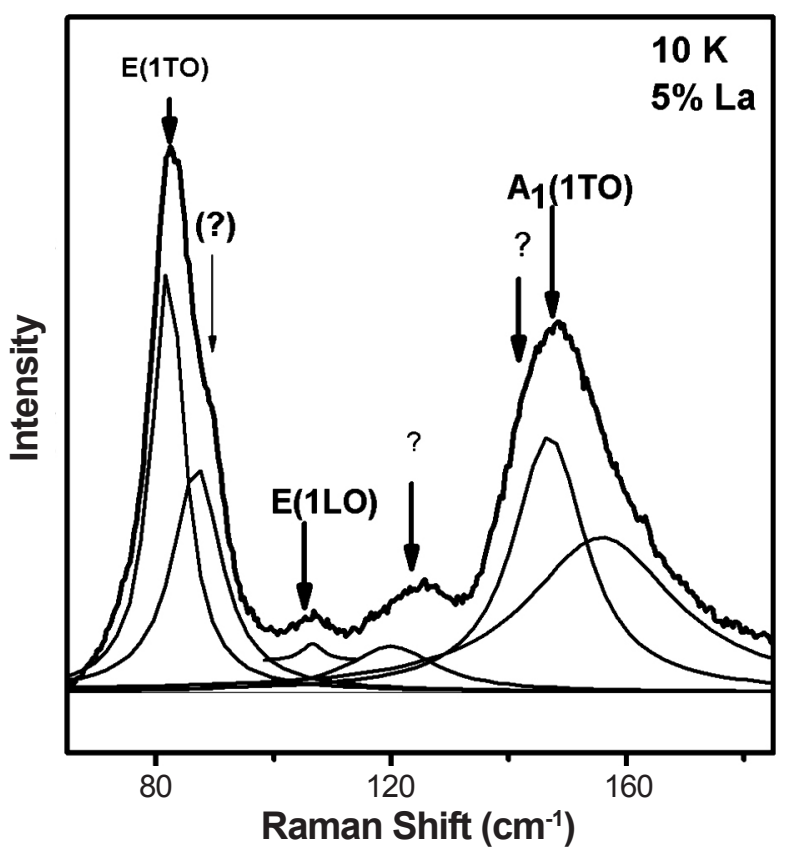

Figure 2: A1 vibrational mode behavior at $10 \mathrm{~K}$ a concentration of $5 \%$ lanthanum.

[Figura 2: Comportamento do modo vibracional Al a $10 \mathrm{~K}$ para 5\% de lantânio.]

are more peaks that those provided by the usual selection rules for this material. In this figure also shows the ferroelectricity decreases with the La concentration, this can be observed by the displacement of low frequency modes and at the same time widening them. Fig. 3 also shows the behavior 

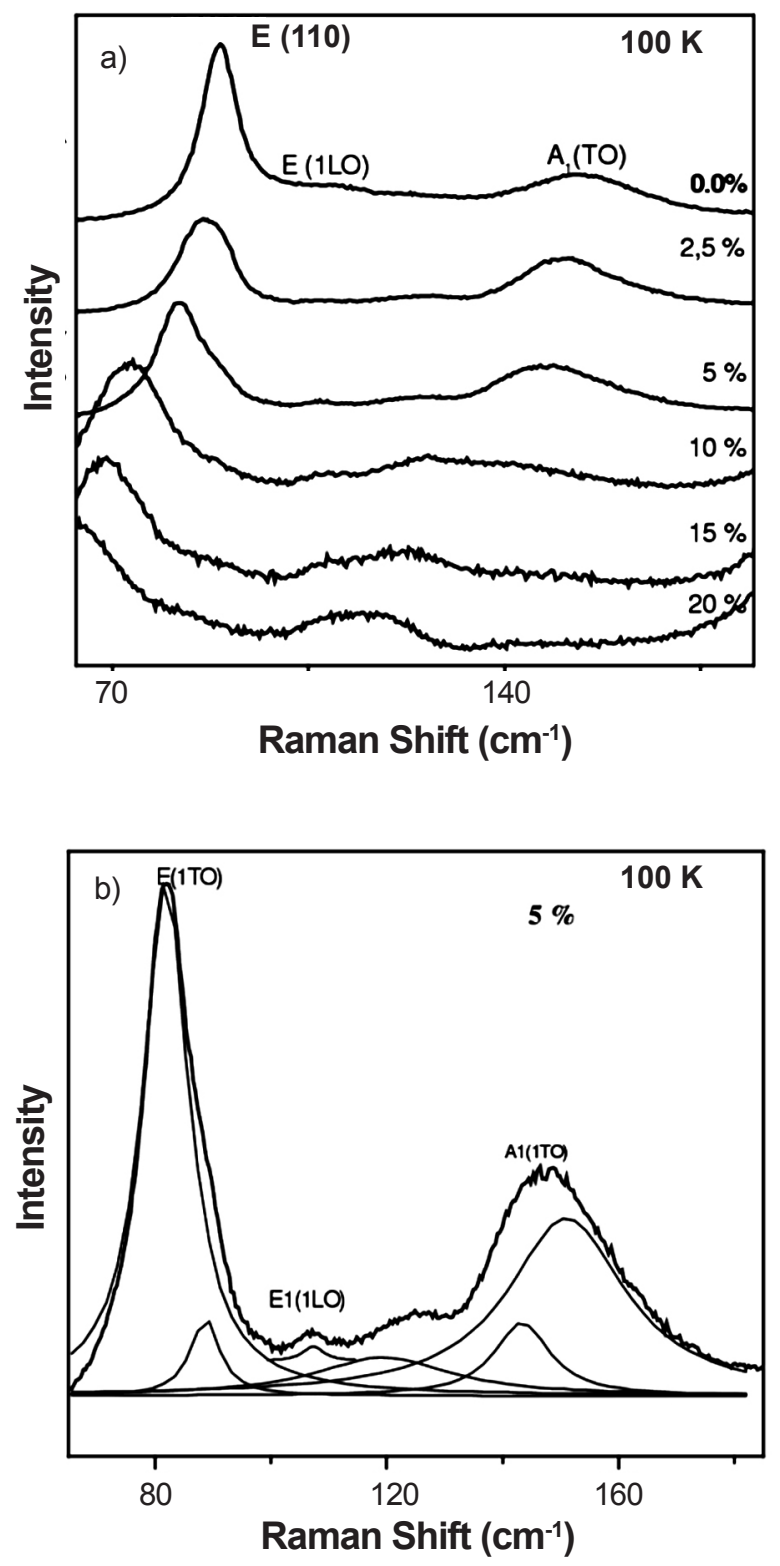

Figure 3: On the left the $\mathrm{Pb}_{1-\mathrm{x}} \mathrm{La}_{\mathrm{x}} \mathrm{TiO}_{3}$ at $100 \mathrm{~K}$ and right extension of the A1 mode behavior and concentration of $5 \% \mathrm{La}$.

[Figura 3: Esquerda: $\mathrm{Pb}_{1-x} \mathrm{La}_{x} \mathrm{TiO}_{3}$ a $100 \mathrm{~K}$; direita: comportamento do modo A1 com a concentração de 5\% de La.]

at a higher temperature $(100 \mathrm{~K})$, as observed this behavior is very similar to low temperature $(10 \mathrm{~K})$. This indicates that behavior is not exclusive at high temperatures. The evolution of the behavior as A1 mode in the Fig. 3 is an indication that indeed there may be inharmonious effects in the material, caused by the concentration of lanthanum in the network. This effect at low temperatures can also be strongly related to the inter-atomic differences in the network, either pure or doped material. At high temperatures is more difficult to separate peaks due to the lengthening of the vibrational modes. This would confirm that once the inharmonic model but extended to a wide range of temperatures (10 -Tc K).

Fig. 4 shows the PLT behavior at room temperature

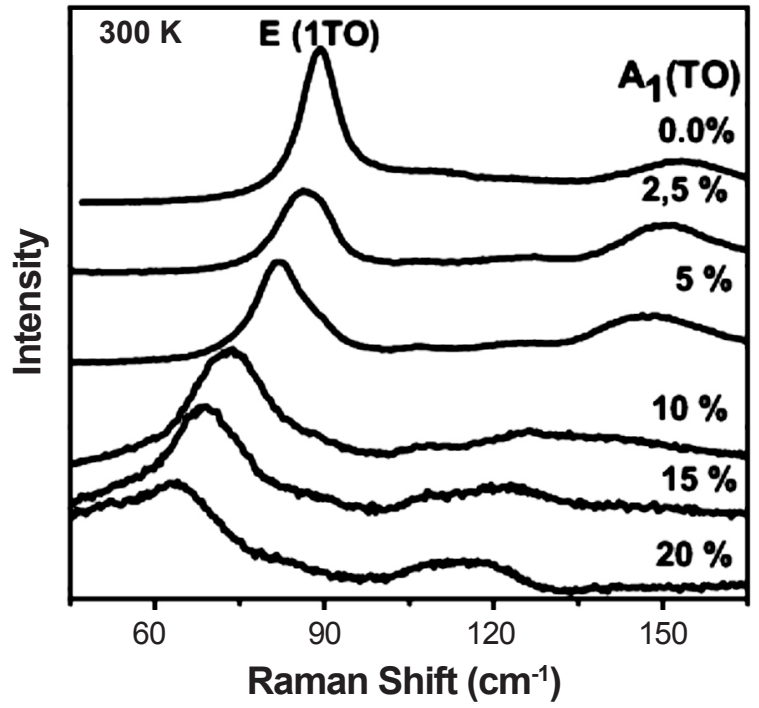

Figure 4: Anomalous behavior of the $\mathrm{A} 1$ mode at room temperature $(300 \mathrm{~K})$.

[Figura 4: Comportamento anômalo do modo Al na temperatura ambiente (300 K).]

$(300 \mathrm{~K})$. At room temperature the vibrational modes are more intense in the pure PT in comparison to the PLT. For high concentrations the A1 (TO) and E1 (LO) modes show an elongation of the peaks in the different samples specially for high concentration and approaching to Tc. The dependence of the La contents at room temperature suggest an qualitative explanation for the perturbation theory containing terms of third and fourth order of anharmonicity. The broadening of the peak at high or room temperatures, it really could be related to multiple phonon processes, as it is greater than the dispersion of first order at more than a phonon is involved in the process, but this does not explain anomaly at low temperatures. Thus, we can say that each of the sub-peaks corresponds to a transition between two neighboring quantum vibrational states. In other words, the frequency of each sub-peak is equal to the energy transition between two vibrational states involved.

\section{CONCLUSIONS}

We show that the low frequency A1 mode in the pure PTO3 or doped with La, this still cannot be adequately explained by existing models in the literature of anharmonicity or polarization. Existing theories explain the anomalous behavior only for high temperatures. We conclude that this effect is caused by the anharmonicity and defects in the network, either by the decrease in the inter-atomic distances at low temperatures and at high temperatures by the displacements of the octahedral BO6 regarding to the $\mathrm{Pb}$ ion sides. Therefore, we suggest a more detailed study theoretically in the entire range of temperatures to explain the anomalous behavior of A1 mode and not only for high temperatures since the effect is also observed at low temperatures and La concentrations. 


\section{REFERENCES}

[1] S. M. Cho, H. M. Jang, T.-Yong Kim, Phys. Rev. B 64, 014103 (2001).

[2] H. M. Jang, M.-Ae Oak, J.-Hoon Lee, Y. K. Jeong, J. F. Scott, Phys. Rev. B 80, 132105 (2009).

[3] A. Crassous, V. Garcia, K. Bouzehouane, S. Fusil, A. H. G. Vlooswijk, G. Rispens, B. Noheda, M. Bibes, A. Barthélémy, Phys. App. Lett. 96, 042901 (2010).

[4] K. Kato, S. Tsukada, J. Kano, T. Yamamoto, S. Kojima, IEEE Trans. Ultrason. Ferroelec. Freq. Control 54, 12 (2007) 2599.

[5] P. Marton, T. Shimada, T. Kitamura, C. Elsasser, Phys. Rev. B 86, 064110 (2011).

[6] G. Burns, B. Scott, Phy. Rev. B 7, 3088 (1973).

[7] E. C. Paris, M. F. C. Gurgel, M. R. Joya, G. P. Casali, C. O. Paiva-Santos, T. M. Boschi, P. S. Pizani, J. A.Varela, E.
Longo, J. Chem. Phys. Solids 71 (2010) 12.

[8] A. Bartasyte, S. Margueron, J. Kreisel, P. Bourson, O. Chaix-Pluchery, L. Rapenne-Homand, J. Santiso, C. Jimenez, A. Abrutis, F. Weiss, M. D. Fontana, Phys. Rev. 79, 104104 (2009).

[9] H. P. Soon, H. Taniguchi, Y. Fujii, M. Itoh, M. Tachibana, Phy. Rev B 78, 172103 (2008).

[10] P.-E. Janolin, P. Bouvier, J. Kreisel, P. A. Thomas, I. A. Kornev, L. Bellaiche, W. Crichton, M. Hanfland, B. Dkhil, Phys. Rev. Lett. 101, 237601 (2008).

[11] Muhtar Ahart, Maddury Somayazulu, R. E. Cohen, P. Ganesh, Przemyslaw Dera, Ho-kwang Mao, Russell J. Hemley, Yang Ren, P. Liermann, Zhigang Wu, Nature 451, 06459 (2008) 545.

[12] C. M. Foster, M. Grimsditch, Z. Li, V. G. Karpov, Phys. Rev. Lett. 71, 8 (1993) 1258.

[13] J. Frantti, V. Lantto, Phys. Rev. B 54, 0163 (1996).

(Rec. 19/08/2011, Ac. 02/10/2011) 